\title{
1115: The long and challenging road for adopting some pest management concepts in sub-Saharan countries
}

\section{Monday, September 26, 2016 04:00 PM - 04:15 PM}

Convention Center - Room W225 A

Areawide IPM, Conservation Biological Control and Habitat Management are some well-established concepts occasionally adopted by some growers in New Zealand, Australia, the United States and certain European countries. Our hypothesis is that, in the countries of sub-Saharan Africa, landscape ecology should help in managing crop pests from a plot to territory level by enhancing, for instance, natural biological control. To initiate the research, the main cereal stem borers (Sesamia calamistis, Busseola fusca, Coniesta ignefusalis) were chosen as a biological model due to their often mentioned economic importance. They were observed in a maize-bean cropping system at Kisumu, Kenya, during the 2011 season, and in a lowland rice landscape in Pelebina, Benin, during a oneyear cycle (2013-2014). In Benin, fields were mapped and smallholder cultural practices were surveyed. Obstacles to adopting this new way of perceiving pest management are described. The constraints encompassed a wide range of aspects, such as acquiring and interpreting remote images within a complex mosaic landscape. Available entomological and botanical knowledge was another limitation, as well as the chosen biological model, which was unable to evaluate biological regulation during the short time of the studies. Difficulties in carrying out long-term studies within projects with short-term funding are other constraints. A worldwide panoramic vision across some other tropical areas where such research has been done is proposed in order to recommend some tips for overcoming the detected limitations. This more holistic approach to pest management seems still in its infancy in sub-Saharan Africa.

\section{Authors}

